Braz J Med Biol Res, September 2012, Volume 45(9) 851-855

doi: 10.1590/S0100-879X2012007500115

Mutation and genomic amplification of the PIK3CA proto-oncogene in pituitary adenomas

C.B. Murat, P.B.S. Braga, M.A.H.Z. Fortes, M.D. Bronstein, M.L.C. Corrêa-Giannella and R.R. Giorgi

The Brazilian Journal of Medical and Biological Research is partially financed by

\section{Q}

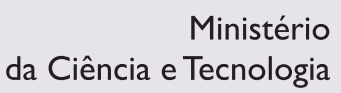

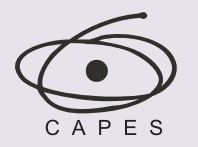

Ministério da Educação
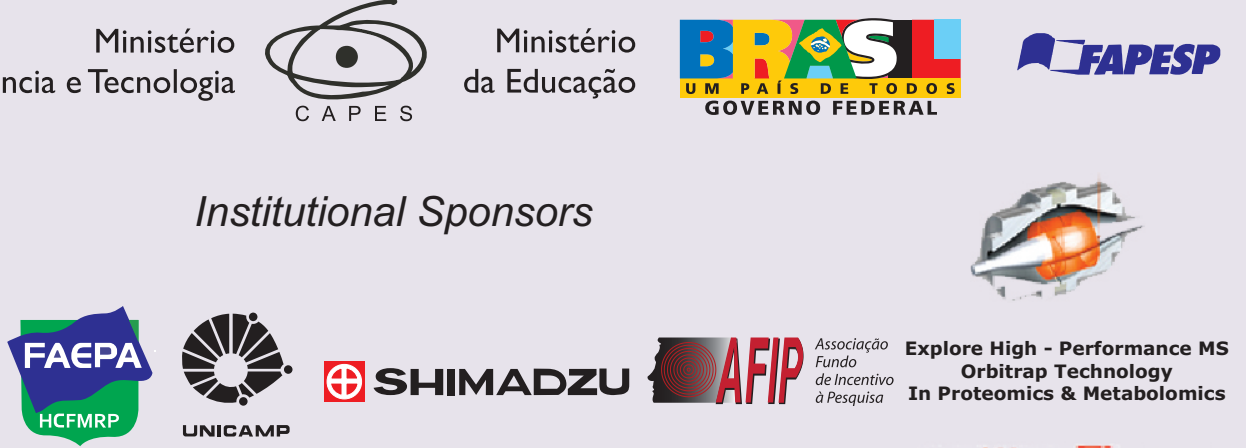

Institutional Sponsors

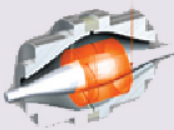

$\oplus$ SHIMADZU UNICAMP

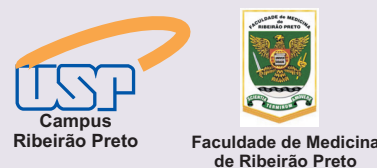
de Ribeirão Preto
de 


\title{
Mutation and genomic amplification of the PIK3CA proto-oncogene in pituitary adenomas
}

\author{
C.B. Murat ${ }^{1}$, P.B.S. Braga ${ }^{1}$, M.A.H.Z. Fortes ${ }^{1}$, M.D. Bronstein ${ }^{2}$, \\ M.L.C. Corrêa-Giannella ${ }^{1}$ and R.R. Giorgi ${ }^{1}$ \\ ${ }^{1}$ Laboratório de Endocrinologia Celular e Molecular (LIM-25), Faculdade de Medicina, \\ Universidade de São Paulo, São Paulo, SP, Brasil \\ 2Unidade de Neuroendocrinologia, Serviço de Endocrinologia, Hospital das Clínicas, \\ Faculdade de Medicina, Universidade de São Paulo, São Paulo, SP, Brasil
}

\begin{abstract}
The tumorigenesis of pituitary adenomas is poorly understood. Mutations of the PIK3CA proto-oncogene, which encodes the p110- $\alpha$ catalytic subunit of PI3K, have been reported in various types of human cancers regarding the role of the gene in cell proliferation and survival through activation of the PI3K/Akt signaling pathway. Only one Chinese study described somatic mutations and amplification of the PIK3CA gene in a large series of pituitary adenomas. The aim of the present study was to determine genetic alterations of PIK3CA in a second series that consisted of 33 pituitary adenomas of different subtypes diagnosed by immunohistochemistry: 6 adrenocorticotropic hormone-secreting microadenomas, 5 growth hormone-secreting macroadenomas, 7 prolactin-secreting macroadenomas, and 15 nonfunctioning macroadenomas. Direct sequencing of exons 9 and 20 assessed by qPCR was employed to investigate the presence of mutations and genomic amplification defined as a copy number $\geq 4$. Previously identified PIK3CA mutations (exon 20) were detected in four cases (12.1\%). Interestingly, the Chinese study reported mutations only in invasive tumors, while we found a PIK3CA mutation in one noninvasive corticotroph microadenoma. PIK3CA amplification was observed in $21.2 \%(7 / 33)$ of the cases. This study demonstrates the presence of somatic mutations and amplifications of the PIK3CA gene in a second series of pituitary adenomas, corroborating the previously described involvement of the PI3K/Akt signaling pathway in the tumorigenic process of this gland.
\end{abstract}

Key words: Pituitary adenomas; PIK3CA proto-oncogene; Genomic amplification; Somatic mutation

\section{Introduction}

The tumorigenesis of pituitary adenomas is poorly understood. The phosphatidylinositol 3-kinases (PI3Ks) are a group of heterodimeric lipid kinases composed of regulatory (85-kDa; p85) and catalytic (110-kDa; p110) subunits that play a key role in cell growth, proliferation, motility, and survival (1-3). The activation of PI3K results in phosphorylation of phosphatidylinositol-4,5-biphosphate $\left(\mathrm{PIP}_{2}\right)$ to phosphatidylinositol-3,4,5-triphosphate $\left(\mathrm{PIP}_{3}\right)$, which acts as an anchor for Akt serine/threonine kinase and 3-phosphoinositide-dependent protein kinase-1 (PDK1), and facilitates phosphorylation of Akt by PDK1, stimulating Akt activity and subsequent phosphorylation of several proteins involved in a variety of intracellular processes, including antiapoptosis $(4,5)$. $\mathrm{PIP}_{3}$ levels are tightly regu- lated by the action of phosphatases such as phosphatase and tensin homologue (PTEN) (6).

Mutations of the PIK3CA proto-oncogene, which encodes the $\mathrm{p} 110-\alpha$ catalytic subunit of PI3K, have been reported in various types of human cancers (7-10) and more than $80 \%$ of PIK3CA mutations are clustered in the helical domain encoded by exon 9 and in the kinase domain encoded by exon 20 (11), as shown with high prevalence in endometrioid, esophageal and pancreatic carcinomas (12-15).

A recent Chinese study (16) has described somatic mutations and amplifications of the PIK3CA gene in a large series of pituitary adenomas, implicating the PI3KJ Akt signaling pathway in the tumorigenic process of this

Correspondence: R.R. Giorgi, Laboratório de Endocrinologia Celular e Molecular (LIM-25), Faculdade de Medicina, USP, Av. Dr. Arnaldo, 455, 01246-903 São Paulo, SP, Brasil. Fax: +55-11-3061-8457. E-mail: rrgiorgi2@hotmail.com

Received January 14, 2012. Accepted June 28, 2012. Available online July 13, 2012. Published August 17, 2012. 
gland. Since a diversity of mutational spectra in different populations had been described for certain neoplasias $(17,18)$, in the present study we investigated genetic alterations in the PIK3CA proto-oncogene in a second series of pituitary adenomas.

\section{Material and Methods}

\section{Tissue specimens and DNA isolation}

Tissue collection was carried out in compliance with the Institutional Ethics Committee (CAPPesq) and in accordance to the Declaration of Helsinki, with informed and free written consent being required from each subject or subject's guardian. From 1994-2009, tumor tissues were obtained from patients diagnosed with pituitary adenomas. During surgery, tumor fragments were collected into sterile containers and immediately frozen in liquid nitrogen. Thirtythree sporadic pituitary adenomas were obtained after surgery. The anatomo-pathological characteristics of these adenomas are shown in Table 1. Pituitary adenomas consisted of 6 adrenocorticotropic hormone (ACTH)-secreting microadenomas, 5 growth hormone $(\mathrm{GH})$-secreting macroadenomas, 7 prolactin (PRL)-secreting macroadenomas, and 15 nonfunctioning (NF) macroadenomas. As control, four normal pituitary tissues were obtained within $8 \mathrm{~h}$ post mortem from subjects without endocrine diseases. The tissue fragments were fragmented in a tissue pulverizer (Mikro-Dismembrator U, B. Braun Melsungen, Germany). Tumor DNA was extracted using the DNeasy kit (Qiagen, USA) according to manufacturer instructions.

\section{Mutation analysis}

Exons 9 and 20 of PIK3CA were analyzed by direct sequencing on an $\mathrm{ABI} 3130 \mathrm{X}$ Genetic Analyzer (Applied Biosystems, USA) after PCR amplification of genomic DNA. $\mathrm{PCR}$ was carried out in $50 \mu \mathrm{L}$ containing $100 \mathrm{ng}$ genomic DNA, $0.2 \mathrm{mM}$ of each primer, $200 \mu \mathrm{M}$ deoxynucleotides, $1 \mathrm{X}$ buffer and $1 \mathrm{U}$ DNA Taq polymerase (GE Healthcare, USA). The nucleotide sequences for the primers were designed using the Primer3 software: exon 9 forward 5'-CAAAGCAATTTCT ACACGAGATCC-3'; exon 9 reverse 5'-GTAAAAACATGCTG AGATCAGCCACAT-3'; exon 20 forward 5'-TGGAATGCC AGAACTACAATCTTT-3', and exon 20 reverse 5'-GGTCTTTGCCTGCTG AGAGTT-3' (Invitrogen, USA). Reactions were carried out under the following cycling conditions: $95^{\circ} \mathrm{C}$ for $5 \mathrm{~min}, 35$ cycles of $95^{\circ} \mathrm{C}$ for $30 \mathrm{~s}$, followed by $56^{\circ} \mathrm{C}$ (exon 9 ) or $62^{\circ} \mathrm{C}$ (exon 20) for $30 \mathrm{~s}$ and $72^{\circ} \mathrm{C}$ for $10 \mathrm{~min}$. The PCR products were subjected to direct sequencing with the use of BigDye Terminator sequencing reagents (Applied Biosystems) with the following cycles: $96^{\circ} \mathrm{C}$ for $15 \mathrm{~s}, 50^{\circ} \mathrm{C}$ for $15 \mathrm{~s}$ and $60^{\circ} \mathrm{C}$ for $4 \mathrm{~min}$ for 35 cycles. All mutated DNA sequences were confirmed by sequencing in the reverse direction.

\section{Copy number analysis}

PIK3CA gene copy number amplification was assessed by qPCR using Platinum SYBR Green qPCR SuperMixUDG (Invitrogen), $100 \mathrm{ng}$ DNA and primers for genomic sequences (PIK3CA forward: 5'-ATCTTTTCTCAATGATGC TTGGCT-3' and PIK3CA reverse: 5'-CTAGGGTGTTTCG AATGTATG-3') and compared with the signal obtained from COL7A1 as reference gene (COL7A1 forward: 5'-ACC CAGTACCGCATCATTGTG-3' and COL7A1 reverse: 5'-TC AGGCTGGAACTTCAGTGTG-3').

PCR was carried out on a Rotor-Gene 6000 instrument (Corbett Life Science, Australia). The reaction consisted of an initial incubation at $95^{\circ} \mathrm{C}$ for $10 \mathrm{~min}$ followed by 40 cycles of $95^{\circ} \mathrm{C}$ for $15 \mathrm{~s}$ and $55^{\circ} \mathrm{C}$ for $1 \mathrm{~min}$. Fluorescence changes were monitored after each cycle. Melting curve analysis was performed at the end of each reaction to confirm PCR product's identity $\left(72^{\circ} \mathrm{C}\right.$ ramping to $99^{\circ} \mathrm{C}$ at $0.2^{\circ} \mathrm{C} / \mathrm{s}$ with continuous fluorescence readings). Standard curves were constructed to assess the amplification efficiency of PIK3CA and COL7A1 using duplicate serial dilutions with seven different DNA concentrations (400 to $6.25 \mathrm{ng}$ ) from a reference sample of DNA obtained from normal pituitary tissue. Since equal amplification efficiencies of target and reference genes were attained $(E>0.9)$, the mathematical model $2^{-\Delta \Delta C t}$ was used to evaluate the relative genomic amplification of PIK3CA. All samples were run in duplicate. DNA obtained from a pool of four normal pituitary tissues was included in the assay as a calibrator sample and DNA extracted from the MCF-7 cell line was used as a positive control for PIK3CA amplification. DNA amplification was defined as values $\geq 4$ (16).

\section{Results}

\section{PIK3CA mutations}

Previously reported PIK3CA mutations were detected in four cases (12\%): 3 of $15(20 \%)$ NF pituitary adenomas and 1 of $6(16.6 \%)$ ACTH-secreting tumors, both in exon 20 (Table 2). No mutations were found in exon 9.
Table 1. Demographic data and anatomo-pathological findings of 33 patients with pituitary adenomas who participated in the present study.

\begin{tabular}{lrcrc}
\hline Pituitary adenomas & $\mathrm{N}$ & $\begin{array}{c}\text { Gender } \\
\text { (male/female) }\end{array}$ & Age (years) & $\begin{array}{c}\text { Tumor size } \\
\text { (micro/macroadenoma) }\end{array}$ \\
\hline ACTH-secreting & 6 & $4 / 2$ & $32.3(13-61)$ & $6 / 0$ \\
GH-secreting & 5 & $2 / 3$ & $30.2(23-55)$ & $0 / 5$ \\
PRL-secreting & 7 & $1 / 6$ & $31(20-64)$ & $0 / 7$ \\
Nonfunctioning & 15 & $6 / 9$ & $44(21-70)$ & $0 / 15$ \\
\hline
\end{tabular}

$\mathrm{ACTH}=$ adrenocorticotropic hormone; $\mathrm{GH}=$ growth hormone; $\mathrm{PRL}=$ prolactin; $\mathrm{mi}-$ croadenoma $=\leq 10 \mathrm{~mm}$; acroadenoma $=\geq 10 \mathrm{~mm}$. 


\section{Amplification of PIK3CA}

The number of copies of the PIK3CA gene in each tumor sample is shown in Figure 1. Genomic amplification was observed in $21.2 \%(7 / 33)$ of the cases; in 4 of 5 (80\%) $\mathrm{GH}$-secreting adenomas, 1 of $6(16.6 \%) \mathrm{ACTH}-$ secreting adenomas and in 2 of $15(13.3 \%)$ NF pitu-

Table 2. PIK3CA mutations found in four pituitary adenomas.

\begin{tabular}{lcccc}
\hline Exon & Functional domain & PIK3CA DNA mutation & Amino acid & Subtype of tumor \\
\hline 20 & Kinase domain & GCC > GAC, C2994A & Ala ${ }^{995} \mathrm{Asp}, \mathrm{A}>\mathrm{D}$ & ACTH \\
20 & Kinase domain & GGC $>$ GGT, C3031T & Gly ${ }^{1007} \mathrm{Gly}, \mathrm{G}>\mathrm{G}$ & NF \\
20 & Kinase domain & TCT $>$ CCT, T3053C & Ser $^{1015} \mathrm{Pro}, \mathrm{S}>\mathrm{P}$ & NF \\
20 & Kinase domain & CAA > CGA, A3108G & Gln ${ }^{1033} \mathrm{Arg}, \mathrm{Q}>\mathrm{R}$ & NF \\
\hline
\end{tabular}

$\mathrm{ACTH}=$ adrenocorticotropic hormone-secreting adenoma; NF = nonfunctioning pituitary adenoma.

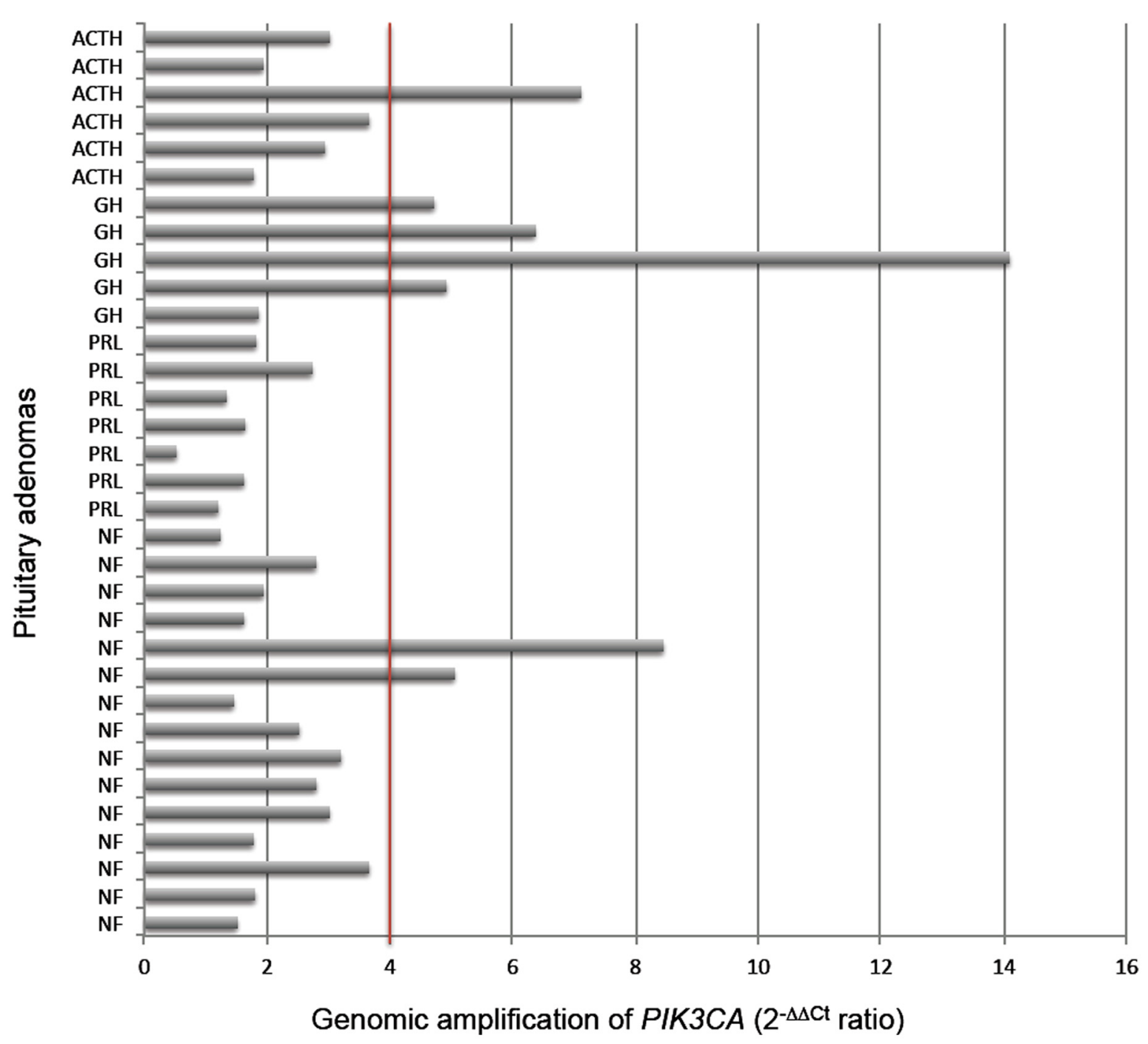

Figure 1. PIK3CA gene copy number detected by $\mathrm{qPCR}$ in different subtypes of pituitary adenomas. Positive amplification is defined as $\geq 4$ copies. $\mathrm{ACTH}=$ adrenocorticotropic hormone-secreting adenoma; $\mathrm{GH}=$ growth hormone-secreting macroadenoma; $\mathrm{PRL}=$ prolactin-secreting macroadenoma; NF = nonfunctioning pituitary adenoma. 
itary adenomas. No genomic amplification was detected in PRL-secreting adenomas.

\section{Discussion}

Several studies have implicated PIK3CA somatic mutations and genomic amplification in the tumorigenic process of different human cancers (19-26). In the present study, we investigated mutations and genomic amplification of the PIK3CA proto-oncogene in 33 sporadic pituitary adenomas. During our experiments, another group of investigators evaluated the association of these genetic alterations in pituitary tumors (16). Given the diversity of mutational spectra in different populations for certain neoplasias $(17,18)$, we decided to continue to examine the incidence of these mutations and amplifications in pituitary tumors of Brazilian patients.

The overall frequency of PIK3CA gene mutations and amplification in the Chinese study of 353 pituitary tumors was $2.3 \%$ (8.8\% of the invasive tumors and $0 \%$ of the noninvasive ones) and $28 \%$ (26.3\% of the noninvasive tumors and $32.9 \%$ of the invasive ones), respectively (16), while in the current series, PIK3CA mutations and amplification were found in 12.1 and $21.2 \%$ of the cases, respectively.

Although it is difficult to compare studies that differ so much in the size of the evaluated population, the present study corroborates the previous report (16) that genetic alterations in the PIK3CA gene are found in pituitary tumors. We only detected mutations in one ACTH-secreting and three NF pituitary adenomas, while Lin et al. (16) also found mutations in two PRL-secreting tumors. Mutations in $\mathrm{GH}$-secreting tumors were not found in any of the two series. Interestingly, the Chinese study reported mutations only in invasive tumors, while we found a PIK3CA mutation in one noninvasive corticotroph microadenoma. Recent reports have shown that PIK3CA knockdown reduces proliferation and invasiveness in different cell lines (27-29).

\section{References}

1. Samuels $Y$, Diaz LA Jr, Schmidt-Kittler O, Cummins JM, DeLong L, Cheong I, et al. Mutant PIK3CA promotes cell growth and invasion of human cancer cells. Cancer Cell 2005; 7: 561-573.

2. Samuels $\mathrm{Y}$, Ericson $\mathrm{K}$. Oncogenic $\mathrm{PI} 3 \mathrm{~K}$ and its role in cancer. Curr Opin Oncol 2006; 18: 77-82.

3. Liu P, Cheng H, Roberts TM, Zhao JJ. Targeting the phosphoinositide 3-kinase pathway in cancer. Nat Rev Drug Discov 2009; 8: 627-644.

4. Raimondi C, Falasca M. Targeting PDK1 in cancer. Curr Med Chem 2011; 18: 2763-2769.

5. Vivanco I, Sawyers CL. The phosphatidylinositol 3-kinase AKT pathway in human cancer. Nat Rev Cancer 2002; 2 : 489-501.

6. Musat M, Korbonits M, Kola B, Borboli N, Hanson MR, Nan-
Defining positive gene amplification as a copy number $\geq 4$, ACTH-secreting tumors (16.6\%), NF pituitary tumors $(13.3 \%)$ and particularly $\mathrm{GH}$-secreting tumors $(80 \%)$ were identified as harboring PIK3CA amplifications, with the highest number being 14 copies in a $\mathrm{GH}$-secreting tumor. Adding to the previous Chinese study, PIK3CA amplification was more common than mutations. Amplification of PIK3CA has been demonstrated to be a mechanism of resistance for PI3K-targeted therapy in cancer (30).

The coexistence of PIK3CA mutations with amplifications in pituitary adenomas seems to be rare; only one case (NF tumor) harbored coexisting PIK3CA copy gain and a gene mutation. These findings suggest that PIK3CA mutation and amplification are independent oncogenic pathways in pituitary tumors (16), as mutually exclusive mechanisms, as already described for thyroid tumors (31); however, the coexistence of these genetic alterations has been reported in breast cancers (32).

The major effector of PI3K is Akt kinase, which phosphorylates target proteins regulating key processes such as cell proliferation and survival. This process is counteracted by the phosphatase encoded by the PTEN tumor suppressor gene, which opposes PI3K activity (33). A recent study has implicated phosphorylated Akt expression associated with PIK3CA mutations in low-stage colorectal cancers (34). In 2005, Musat et al. (6) reported a higher expression of phosphorylated Akt in pituitary tumors in comparison to the normal gland in the absence of PTEN mutations. Thus, it is reasonable to suppose that increased Akt phosphorylation in pituitary adenomas could result from activation of the PI3K pathway following PIK3CA mutation or amplification.

In summary, this study demonstrates the presence of somatic mutations and amplifications of the PIK3CA gene in a second series of pituitary adenomas, corroborating the previously described involvement of the PI3K/Akt signaling pathway in the tumorigenesis of this gland $(16,35,36)$ and its molecular potential for targeted therapies $(3,27-29,37)$

zer AM, et al. Enhanced protein kinase B/Akt signalling in pituitary tumours. Endocr Relat Cancer 2005; 12: 423-433.

7. Gallia GL, Rand V, Siu IM, Eberhart CG, James CD, Marie SK, et al. PIK3CA gene mutations in pediatric and adult glioblastoma multiforme. Mol Cancer Res 2006; 4: 709-714.

8. Kozaki K, Imoto I, Pimkhaokham A, Hasegawa S, Tsuda H, Omura $\mathrm{K}$, et al. PIK3CA mutation is an oncogenic aberration at advanced stages of oral squamous cell carcinoma. Cancer Sci 2006; 97: 1351-1358.

9. Woenckhaus J, Steger K, Sturm K, Munstedt K, Franke FE, Fenic I. Prognostic value of PIK3CA and phosphorylated AKT expression in ovarian cancer. Virchows Arch 2007; 450: 387-395.

10. Santarpia M, Altavilla G, Margeli M, Cirauqui B, Mesiti M, Cavallari V, et al. PIK3CA mutations and BRCA1 expression 
in breast cancer: potential biomarkers for chemoresistance. Cancer Invest 2008; 26: 1044-1051.

11. Samuels $Y$, Wang Z, Bardelli A, Silliman N, Ptak J, Szabo $S$, et al. High frequency of mutations of the PIK3CA gene in human cancers. Science 2004; 304: 554.

12. Hayes MP, Wang H, Espinal-Witter R, Douglas W, Solomon GJ, Baker SJ, et al. PIK3CA and PTEN mutations in uterine endometrioid carcinoma and complex atypical hyperplasia. Clin Cancer Res 2006; 12: 5932-5935.

13. Rudd ML, Price JC, Fogoros S, Godwin AK, Sgroi DC, Merino $\mathrm{MJ}$, et al. A unique spectrum of somatic PIK3CA (p110alpha) mutations within primary endometrial carcinomas. Clin Cancer Res 2011; 17: 1331-1340.

14. Phillips WA, Russell SE, Ciavarella ML, Choong DY, Montgomery KG, Smith K, et al. Mutation analysis of PIK3CA and PIK3CB in esophageal cancer and Barrett's esophagus. Int J Cancer 2006; 118: 2644-2646.

15. Schonleben F, Allendorf JD, Quu W, Li X, Ho DJ, Ciau NT, et al. Mutational analyses of multiple oncogenic pathways in intraductal papillary mucinous neoplasms of the pancreas. Pancreas 2008; 36: 168-172.

16. Lin $\mathrm{Y}$, Jiang $\mathrm{X}$, Shen $\mathrm{Y}$, Li M, Ma H, Xing M, et al. Frequent mutations and amplifications of the PIK3CA gene in pituitary tumors. Endocr Relat Cancer 2009; 16: 301-310.

17. Minamoto T, Mai M, Ronai Z. Environmental factors as regulators and effectors of multistep carcinogenesis. Carcinogenesis 1999; 20: 519-527.

18. Pernick NL, Sarkar FH, Philip PA, Arlauskas P, Shields AF, Vaitkevicius VK, et al. Clinicopathologic analysis of pancreatic adenocarcinoma in African Americans and Caucasians. Pancreas 2003; 26: 28-32.

19. Samuels $Y$, Velculescu VE. Oncogenic mutations of PIK3CA in human cancers. Cell Cycle 2004; 3: 1221-1224.

20. Angulo B, Suarez-Gauthier A, Lopez-Rios F, Medina PP, Conde $\mathrm{E}$, Tang $\mathrm{M}$, et al. Expression signatures in lung cancer reveal a profile for EGFR-mutant tumours and identify selective PIK3CA overexpression by gene amplification. J Pathol 2008; 214: 347-356.

21. Hou P, Liu D, Shan Y, Hu S, Studeman K, Condouris S, et al. Genetic alterations and their relationship in the phosphatidylinositol 3-kinase/Akt pathway in thyroid cancer. Clin Cancer Res 2007; 13: 1161-1170.

22. Okudela K, Suzuki M, Kageyama S, Bunai T, Nagura K, Igarashi $\mathrm{H}$, et al. PIK3CA mutation and amplification in human lung cancer. Pathol Int 2007; 57: 664-671.

23. Wu G, Xing M, Mambo E, Huang X, Liu J, Guo Z, et al. Somatic mutation and gain of copy number of PIK3CA in human breast cancer. Breast Cancer Res 2005; 7: R609-R616.

24. Yamamoto S, Tsuda H, Takano M, Iwaya K, Tamai S, Matsubara O. PIK3CA mutation is an early event in the development of endometriosis-associated ovarian clear cell adenocarcinoma. J Pathol 2011; 225: 189-194.

25. Choy E, Hornicek F, Macconaill L, Harmon D, Tariq Z, Garraway $L$, et al. High-throughput genotyping in osteosarcoma identifies multiple mutations in phosphoinositide-3-kinase and other oncogenes. Cancer 2012; 118: 2905-2914.

26. Ji M, Guan H, Gao C, Shi B, Hou P. Highly frequent promoter methylation and PIK3CA amplification in non-small cell lung cancer (NSCLC). BMC Cancer 2011; 11: 147.

27. Weber GL, Parat MO, Binder ZA, Gallia GL, Riggins GJ. Abrogation of PIK3CA or PIK3R1 reduces proliferation, migration, and invasion in glioblastoma multiforme cells. Oncotarget 2011; 2: 833-849.

28. Zhou XK, Tang SS, Yi G, Hou M, Chen JH, Yang B, et al. RNAi knockdown of PIK3CA preferentially inhibits invasion of mutant PIK3CA cells. World J Gastroenterol 2011; 17 : 3700-3708

29. Guerreiro AS, Fattet S, Fischer B, Shalaby T, Jackson SP, Schoenwaelder SM, et al. Targeting the PI3K p110alpha isoform inhibits medulloblastoma proliferation, chemoresistance, and migration. Clin Cancer Res 2008; 14: 67616769.

30. Liu P, Cheng H, Santiago S, Raeder M, Zhang F, Isabella A, et al. Oncogenic PIK3CA-driven mammary tumors frequently recur via PI3K pathway-dependent and PI3K pathwayindependent mechanisms. Nat Med 2011; 17: 1116-1120.

31. Wang Y, Hou P, Yu H, Wang W, Ji M, Zhao S, et al. High prevalence and mutual exclusivity of genetic alterations in the phosphatidylinositol-3-kinase/akt pathway in thyroid tumors. J Clin Endocrinol Metab 2007; 92: 2387-2390.

32. Kadota M, Sato M, Duncan B, Ooshima A, Yang HH, DiazMeyer $\mathrm{N}$, et al. Identification of novel gene amplifications in breast cancer and coexistence of gene amplification with an activating mutation of PIK3CA. Cancer Res 2009; 69: 73577365.

33. Tena-Suck ML, Ortiz-Plata A, de la Vega HA. Phosphatase and tensin homologue and pituitary tumor-transforming gene in pituitary adenomas. Clinical-pathologic and immunohistochemical analysis. Ann Diagn Pathol 2008; 12: 275-282.

34. Baba Y, Nosho K, Shima K, Hayashi M, Meyerhardt JA, Chan AT, et al. Phosphorylated AKT expression is associated with PIK3CA mutation, low stage, and favorable outcome in 717 colorectal cancers. Cancer 2011; 117: 1399-1408.

35. Suhardja A, Kovacs K, Rutka J. Role of transcription factors in the pathogenesis of pituitary adenomas: a review. $J$ Neurooncol 2001; 55: 185-193.

36. Grossman $A B$, Korbonits M. Akting and cycling: a tale of the pituitary. Horm Res 2004; 62 (Suppl 3): 117-123.

37. Jamieson S, Flanagan JU, Kolekar S, Buchanan C, Kendall JD, Lee WJ, et al. A drug targeting only p110alpha can block phosphoinositide 3-kinase signalling and tumour growth in certain cell types. Biochem J 2011; 438: 53-62. 